\title{
A case study of morphogenetic change in long- term offshoring
}

Article in International Journal of Information Management · August 2013

DOI: 10.1016/j.ijinfomgt.2013.03.006

CITATION

1

1 author:

\section{Rajesh Mirani}

University of Baltimore

28 PUBLICATIONS 550 CITATIONS

SEE PROFILE
READS

44

Some of the authors of this publication are also working on these related projects:

Project (To be Decided) View project 
Provided for non-commercial research and education use. Not for reproduction, distribution or commercial use.

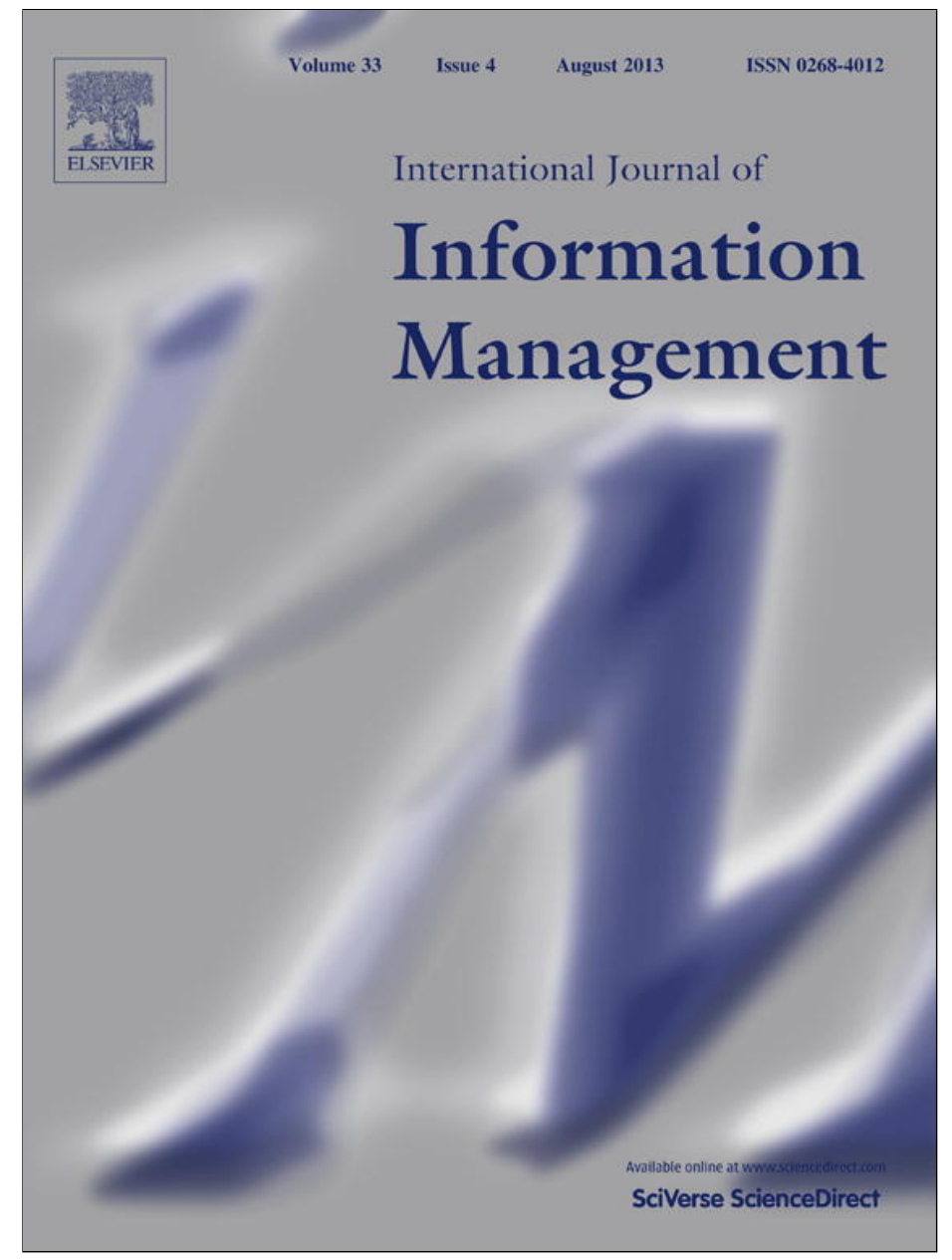

This article appeared in a journal published by Elsevier. The attached copy is furnished to the author for internal non-commercial research and education use, including for instruction at the authors institution and sharing with colleagues.

Other uses, including reproduction and distribution, or selling or licensing copies, or posting to personal, institutional or third party websites are prohibited.

In most cases authors are permitted to post their version of the article (e.g. in Word or Tex form) to their personal website or institutional repository. Authors requiring further information regarding Elsevier's archiving and manuscript policies are encouraged to visit:

http://www.elsevier.com/authorsrights 


\title{
A case study of morphogenetic change in long-term offshoring
}

\author{
Rajesh Mirani* \\ Information Systems E' Decision Science, Merrick School of Business, University of Baltimore, 11 W. Mt. Royal Avenue, Baltimore, MD 21201, United States
}

\section{A R T I C L E I N F O}

Article history:

Available online 22 April 2013

\section{Keywords:}

Case study

Critical realism

Information technology offshoring

Inter-organizational relationships

Morphogenesis

Organizational change

\begin{abstract}
A B S T R A C $T$
This paper applies a morphogenetic change framework to the case study of a financial information services provider's relationships with offshore IT application vendors over a six year period, in order to discover the underlying causal mechanisms. The analysis finds the progression to have consisted of a sequence of three major organizational changes, where each change was characterized by a morphogenetic cycle of three phases - Structural and Cultural Conditioning, Socio-Cultural Interactions, and Structural and Cultural Elaboration. In the first phase of each change cycle, structural and cultural outcomes of antecedent cycles conditioned the context as perceived by managerial actors. In the second phase, these conditioning factors interacted with the organization's prevailing socio-cultural dynamics to influence managerial decisions and to effect change. Finally, in the third phase, the emergent consequences of their decisions further altered the structural and cultural landscape, thus conditioning the context for the subsequent change cycle. While the specific organizational mechanisms activated varied from one cycle to the next, the overall analysis collectively revealed the company's quest for more effective vendor relationships. It was seen to have struggled with inconsistencies in its view of a captive vendor's role in the first cycle, and a lack of standard processes with multiple vendors in the second cycle, before establishing closer, comprehensive, successful relationships with two vendors in the third cycle. These findings serve to validate the utility of the morphogenetic analytical framework in uncovering change factors unique to specific offshoring contexts.
\end{abstract}

(c) 2013 Elsevier Ltd. All rights reserved.

\section{Introduction}

Recent research with implications for inter-organizational relationships between clients and offshore IT vendors may be classified into two streams. The first stream broadly explores, describes, or prescribes the nature of client-vendor associations, in terms of a variety of structures, coordination and governance mechanisms, or relational intensity (e.g., Beulen, Ribbers, \& Roos, 2011; Burns, 2008; Davis, Ein-Dor, King, \& Torkzadeh, 2006; Gewald \& Dibbern, 2009; Gupta, Seshasai, Mukherji, \& Ganguly, 2007; Haried \& Ramamurthy, 2009; Kotlarsky \& Oshri, 2008; Lacity, Willcocks, \& Khan, 2011; Ramanujan \& Sandhya, 2006). The second stream focuses on the enhancement of specific attributes or outcomes of relationships, including trust, information and communication, domain knowledge, services provided, etc. (Alami, Wong, \& McBride, 2008; Avison \& Banks, 2008; Beulen, Tiwari, van Heck, 2011b; Cha, Pingry, \& Thatcher, 2008; Kelly \& Noonan, 2008; Mathew, 2011; Rashid, 2012). Together, the two streams have provided valued insights pertinent to the management of long-term vendor relationships. The resulting literature on the subject has built up a core of best practices, accepted by both

\footnotetext{
* Tel.: +1 410837 5261; fax: +1 4108375722.

E-mail address: rmirani@ubalt.edu
}

researchers and practitioners. This valuable knowledge base, however, is founded on a somewhat deterministic, static philosophy at the core of both contributing streams. For example, the relationships stream provides some useful guidance on evolving issues in vendor relationships, but despite its tacit acknowledgment of such variations, largely ignores the diversity in underlying organizational and inter-organizational mechanisms, capable of taking each separate relationship down a different change path. Likewise, the stream that addresses specific attributes or outcomes of relationships provides deep insights into their respective phenomena, but gives short shrift to how these phenomena might relate to a broader set of factors that collectively have a greater impact on relationships. The two streams, therefore, collectively emphasize the ' $w$ hat' and 'why' aspects of relationships, albeit with varying breadth and depth. Their common objective appears to be the enablement of client organizations to establish more predictable and controllable vendor relationships. Ironically, though, this objective is unlikely to be significantly achieved without a systematic effort to understand the dynamics that influence relationship changes - in other words, addressing the question of how relationships evolve. Such an understanding could well enable relationships to be steered or channeled into desired paths, but achieving that requires extending the focus of studies beyond immediate, technological environments, to include broader, organizational factors that impact client-vendor relationships. It also calls for a more 
open-ended, exploratory approach in identifying internal and institutional sources of such influencing factors, so that any interactions among them that have the potential to affect relationships may also be studied.

This paper attempts a step in that direction, using the case study research method (Yin, 2009). It does so by presenting the detailed case of a large B2B company that is in the business of providing financial information services, and its struggles with offshored applications. The case documents the client company's struggles with multiple vendor relationships over a six year period. Its analysis follows an explanatory, critical realist paradigm in assessing the causal mechanisms behind the events, actions, and outcomes comprising the three major organizational changes in this progression. The analysis of the case follows an adaptation of morphogenesis theory to uncover these causal mechanisms, and is presented from the perspective of the client organization.

The rest of this paper is organized as follows. Section 2 introduces the theoretical foundations used for the analysis-morphogenesis theory, followed by a description of its adaptation for this study. Section 3, which comprises the paper's analytical core, presents the case study and its analysis, and describes the major findings. Section 4 discusses the implications of these findings. This is followed by the study's conclusion in Section 5.

\section{Theoretical foundations}

\subsection{Morphogenesis}

Morphogenesis is an analytical technique for investigating the structuring of social systems over time. Propounded by Archer (1982, 1988, 1995, 2010), it provides a systematic framework for assessing processes of organizational change. The elements of this framework make it possible to capture change in terms of roles played by a system's structure and culture on one hand, and agency on the other, as well as interactions between them. Morphogenetic change is envisioned as a sequence of cycles, in which each cycle has three, partially overlapping phases - Conditioning, Interaction, and Elaboration. A hallmark of morphogenesis is that the Interaction phase, entailing agent actions, is considered subject to being conditioned or influenced by structural and cultural properties that pre-date it. At the same time, actions are also considered emergent, in the sense that the knowledge of influencing properties cannot in any way help predict them. Further, according to the theory, these systemic influences do not necessarily diminish upon the appearance of emergent action. Rather, the nature of actual actions undertaken may in turn affect the durations of the original influencing properties - speeding up their decay, slowing it down, or stopping it altogether. Therefore, performed action may transform the very system that pre-dates and influences it, or, alternatively, reinforce and consolidate its premises. The former serves to accomplish morphogenetic change while the latter perpetuates morphostatis, i.e., a continuation of the existing context and dynamics. Finally, Elaboration, which follows up on Interaction, is a consolidation phase in which specific 'social possibilities' played up during the second phase are reemphasized and reinforced. Properties thereby strengthened become a part of the conditioning context, or, the first phase, for the next morphogenetic cycle in the sequence.

The morphogenetic framework is particularly well suited for analyzing long-term change in IT offshoring, for various reasons. First, its assumptions and tenets are concerned with uncovering organizational mechanisms on a context-by-context basis. While the framework certainly enables the identification of organizational actions responsible for forging an overall path of change as it might in the case of, say, evolving captive center models (e.g.,
Oshri, 2011), it also makes room for the discovery of other intricacies, e.g., how specific actions came to be - or, the processes that might have caused them. The Interaction phase is particularly useful in this regard, given its emphasis on exploring how change may be influenced by interplays between a system's interpersonal dynamics and its pre-conditioned context. Second, long-term offshoring entails inter-organizational environments, with changing players and relationships. Agent actions in these environments are likely to be subject to both constraining and enabling influences beyond one's control, and these are analytically well captured by means of the Conditioning and Elaboration tools of the framework. In particular, the Elaboration phase provides a robust basis for capturing the logic of emergent outcomes, and the Conditioning phase serves to carry forward the impacts of emergent consequences from one change cycle to the next. Third, the technology-intensiveness of offshoring environments imbues them with task properties likely to play critical change roles, and this is well-matched by the framework's explicit consideration of structure. Thus, for example, the structural contexts of well-defined offshored tasks are likely to differ from those of poorly defined ones, and the morphogenetic framework provides ample room for assessing the differential social interactions that might characterize different types of tasks.

The explanatory orientation of the morphogenetic framework is highly consonant with the philosophical tradition called 'critical realism' (Bhaskar, 1975, 1979). A core principle of the latter is that empirical observations of any functioning system may be used to derive insights on the 'power,' or, potential, of the system's major entities/objects/factors to precipitate events or outcomes by activating specific organizational mechanisms. While the exact nature of these mechanisms varies from one context to another, they typically address the 'how' aspect of the phenomena being investigated. In addition, the critical realist school of thought emphasizes that inferences drawn this way may be legitimately extended to events beyond those directly observed. Critical realists hold that the overarching purpose of all studies of a given system is to refine these inferences on many levels over time, bringing them ever closer to its objective reality, with the understanding that this reality will never be completely captured.

The use of the morphogenetic perspective is rather rare in information systems research. One example of its application is by Mutch (2010), who discusses in detail how the framework may be applied to study the use of information and communication technologies, and also exhorts more IS researchers to adopt it in their studies. Nevertheless, several articles in the literature have addressed the potential of critical realism to inform studies in the area (Basden, 2011; Beckinsale \& Ram, 2011; Bridgman \& Willmott, 2006; Carlsson, Henningsson, Hrastinski, \& Keller, 2011; De Vaujany et al., 2011; Dobson, Myles, \&Jackson, 2007; Dobson, 2001; Edwards, 2007; Fox, 2009; Kakabadse, Kakabadse, \& Kouzmin, 2007; Markus \& Silver, 2008; Mingers, 2000; Mitev \& de Vaujany, 2012; Mora et al., 2007; Morton, 2006; Mourmant, Gallivan, \& Kalika, 2009; Mutch, 2002; Smith, 2010; Stahl, Tremblay, \& Lerouge, 2011; Volkoff, Strong, \& Elmes, 2007; Wikgren, 2005; Wiredu, 2012).

\subsection{Analysis framework}

The case analysis reported here uses a research framework put together by synthesizing Archer's respective morphogenetic frameworks for structural and cultural change. Both are comprised of three-step change cycles that parallel each other in form and content (Archer, 1982, 1988, 1995, 2010). Cultural change, for example, is represented by the following cycle:

\section{Cultural Conditioning $\rightarrow$ Socio-Cultural Interaction}

$\rightarrow$ Cultural Elaboration 


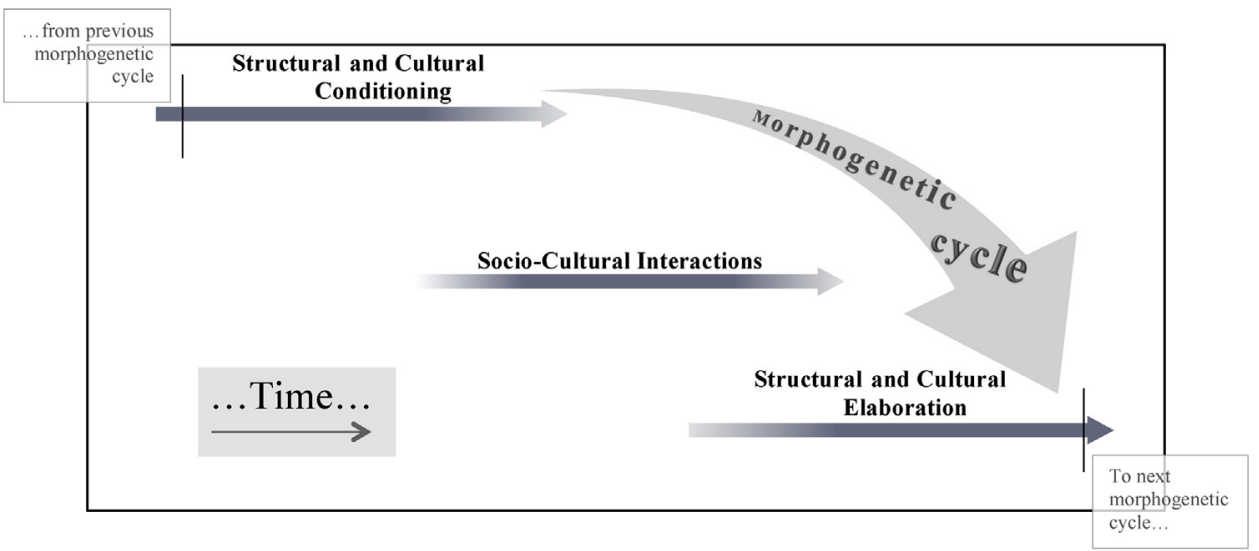

Fig. 1. Morphogenetic change analysis framework.

The first phase in this cycle, cultural conditioning, reflects systemic cultural influences on the context, from the emergent outcomes of preceding change cycles. The strength of these conditioning influences is in direct proportion to the extent of logical consistencies among them, i.e., the overall cohesiveness of the situational cultural logic. In the second phase, socio-cultural interaction, these influences interact with the degree of causal cohesion (i.e., cultural uniformity) produced by socio-cultural dynamics between the system's actors. The manner in which this interplay occurs determines whether the cultural system remains stable or undergoes change. Thus, compatibilities or incompatibilities between parts of the conditioning cultural system, when mapped onto conflict-free or conflict-ridden relationships between actors at the socio-cultural level, significantly affect whether actors choose to stay with their existing belief systems or seek to change them. Their courses of action are also affected by causal relations between groups and individuals at the socio-cultural level. For example, socio-cultural asymmetries may suppress actors' degrees of freedom or even their knowledge of inconsistencies, perversely serving to stabilize and even preserve such asymmetries. Finally, in the third phase, cultural elaboration, the consequences of changes set in motion from the second phase are affected by newly emergent cultural properties and the logical relationships among them. Consequences thus actualized become the basis for the cultural conditioning phase of the next morphogenetic cycle, and so on. Thus, the essence of cultural morphogenesis is that an incumbent cultural system first conditions the context, and then interacts with socio-cultural dynamics among actors to produce both actions as well as an altered cultural system, whose properties in turn influence the outcomes of actions.

Likewise, structural change follows a similar cycle:

Structural Conditioning $\rightarrow$ Social Interaction

\section{$\rightarrow$ Structural Elaboration}

Just as cultural conditioning initiates cultural change, structural morphogenesis begins with structural conditioning, in which emergent structural outcomes of preceding change cycles serve to condition the context. Once again, the more the logical consistencies among the conditioning factors, the greater is their cohesive influence. In the second phase, social interaction, these factors exert causal influences on agent actions, and their interplays with the latter determine whether morphogenesis or morphostatis occurs. Finally, the third phase, structural elaboration, serves to either preserve or change existing structural relationships. In the event of morphogenesis, existing structural relationships are modified, and new ones may emerge. Alternatively, morphostatis reproduces the existing structure.

Fig. 1 depicts the analysis framework for this study, comprised of three stages formed by combining the respective stages of Archer's cultural and structural change frameworks.

\section{The case study}

This section presents the case study of a financial information services provider, and an analysis of the case using the framework above. Data collection for this study was done through detailed interviews of four IT managers who had been responsible for key offshoring decisions and and/or had close knowledge of the company's vendor relationships. The job titles of these managers were, respectively, Chief Technology Officer - Asia-Pacific, Director of Product Development Technology, Senior Vice President of Development and Support, and Assistant Vice President of Development. All four had ten-plus years of work experience. Approximately $25 \mathrm{~h}$ of interviews were conducted with these individuals. The longitudinal case context covers a period of more than six years, beginning with the establishment of an offshore applications support subsidiary, and the use of a staff supplementation model for its personnel to work onshore with the company's own IT staff. It ends with a highly mature state of offshoring, characterized by alliancelike relationships with two independent offshore vendors. In broad terms, the context spans the long-term evolution of the company's approach to offshoring, starting with exploration, and culminating in optimized processes.

Sections 3.1 and 3.2 respectively provide an overview of the company, and shed light on the organizational importance of its applications portfolio. Section 3.3 presents descriptive, snapshot characterizations of the company's offshore vendor relationships at three key stages in the overall temporal sequence, in order to briefly convey the three major organizational changes comprising the evolutionary process. Following this, Section 3.4 applies a morphogenetic analytical lens to the entire process, in order to systematically uncover the organizational mechanisms behind each change cycle, as well as the imperatives responsible for transitions from one cycle to the next. Thus, change cycles are analyzed and discussed in terms of morphogenesis phases such as Structural Conditioning, Socio-Cultural Interactions, and Structural and Cultural Elaboration. Linkages between successive cycles are investigated in terms of the power of emergent outcomes from one cycle to condition the context for the next cycle. The implications of these findings are discussed in Section 4. 


\subsection{The company}

Biznally ${ }^{1}$ is a major global provider of B2B financial information products and services. With its headquarters in the U.S., it conducts most of its business in the North American continent. It also has a major presence in Europe, Asia-Pacific, and South America, with separate units at various locations for sales, support, and fulfillment. As an industry leader in business information for many years, its traditional products pertain to the management of credit risk for a company's financial transactions or alliances with other organizations. Newer products also include consolidated market segment or industry reports, as well as services targeted at managing entire supply chains for large customers. Although Biznally has few real competitors, similar products are offered by credit bureaus, some credit card companies, and a few business intelligence vendors. The company's core competence in ably assessing an organization's credit worthiness has made its name synonymous with the types of products it offers, a stable status it has enjoyed for a very long time. Biznally's annual sales exceed $\$ 1$ billion. Given the information intensity of its products, the company's global IT group is considered a very important and powerful arm of the organization. Annual IT spending currently amounts to approximately one quarter of the total corporate budget.

\subsection{Applications portfolio}

Global applications development at Biznally has historically comprised a large chunk of annual spending. The company as a whole has revenues of about US $\$ 1.4$ billion and a budget of about US \$ 1.1 billion. Annual technology expenditures amount to approximately US \$300 million, of which development costs account for $40-50 \%$. Other than its internal and back-office applications such as financials and billing, the company's applications portfolio comprises of two categories - product-oriented applications, and process-oriented applications. Applications in the first category directly support its business information products in the realms of credit risk management, market reports, and supply chain management. In particular, credit risk management products generate approximately $70 \%$ of the company's revenue. As their information content is reusable, it is highly leveraged into customized reports, at negligible marginal cost. In light of their information intensity and profitability, the customized, in-house applications that support the generation of these products have always been considered critical to the company's operations. However, given that these products have been gradually honed and standardized over many years, the supporting applications have essentially come to automate highly structured and well-defined transactional processes. Applications in the second category comprise of functionalities to support the generation of products mentioned in the first, by enabling generic information functions or processes such as data collection, order execution, sales, and customer service.

\subsection{Offshore vendor relationships}

This section presents an overview of the progressive evolution of Biznally's relationships with overseas vendors for applications maintenance and development. The purpose of this summary is to prepare the foundation for a more detailed description of this progression, together with a formal analysis of the major organizational changes therein, both of which will be presented in

\footnotetext{
${ }^{1}$ Biznally is a fictitious name for a real organization, as are the other two names mentioned in this article. To maintain confidentiality yet preserve the integrity of this case study, some factual information pertaining to all three organizations has been carefully altered.
}

Section 3.4. Therefore, it highlights salient aspects of the evolution of these relationships, but leaves out details pertaining to the organizational mechanisms by which such changes were crystallized and implemented. Examples of omissions from the brief description here include relevant information on organizational culture, management style, reasons and rationales for organizational decisions/actions, intermediate outcomes, and influences of feedback loops from these outcomes on other decisions/actions. These details will be presented and discussed extensively in Section 3.4.

As stated earlier, applications development at Biznally has historically comprised a large chunk of its technology expenditures. Ten years ago, the company established a new, captive, offshore subsidiary called the Technology Excellence Center (TEC), with the mission of providing it with technology and application services. The subsidiary was to compete in the open marketplace for Biznally's business.

To actualize earned contracts, Biznally had TEC personnel work in onshore teams on its U.S. premises, together with its own inhouse applications specialists. The work entrusted to these hybrid teams typically consisted of small coding enhancements to approximately one hundred mature applications. After two years of using its personnel onshore for 'staff supplementation,' Biznally's upper management spun off and sold TEC to a foreign conglomerate called Knowlaware, which subsequently restructured the technology center into an independent division. Under its new name, the center continued to serve Biznally, which soon started allowing it to complete some work entirely overseas. Around this time, Biznally also handed off small coding contracts to other offshore applications vendors. All vendors were typically assigned coding enhancement and basic testing responsibilities only, entailing applications and technologies deemed stable and mainstream.

To transition from offshoring exploration to maturity, Biznally next put together an Application Management Plan for the future. This plan entailed a set of service level agreements defined by Biznally and/or its clients, for all of its vendors to follow. It also spelled out a vision for Biznally to nurture a handful of select vendors in operating Centers for Software Excellence (CSEs), which would gradually take over most of Biznally's applications development and maintenance work. Agreements were set up with two such vendors. One was Biznally's old captive partner, TEC - now known as Knowlaware, and the other was Knowlaware's competitor, N-Stint.

Other elements of the plan included commitments toward information requirements determination methodologies, comprehensive applications documentation, a maintenance management framework, and an outline of roles and responsibilities for Biznally and vendor personnel.

\subsection{Morphogenetic analysis}

The overview above summarizes three major organizational changes. These will henceforth be referred to as Change A, Change B, and Change $C$, respectively. Each change lasted approximately two years. Change A was Biznally's establishment of TEC, and the utilization of its personnel for staff supplementation. Change B was TEC's spin-off to Knowlaware, and a broadening of Biznally's resource base to include other offshore vendors. Change $C$ was the preparation and implementation of an Application Management Plan for select vendors. Each of these three changes will now be analyzed sequentially and systematically, by expanding on the details omitted from the brief description above, and placing these details into a morphogenesis framework comprising of the phases of Structural and Cultural Conditioning, Socio-Cultural Interactions, and Structural and Cultural Elaboration. A key notion in the morphogenesis framework is the recognition of emergent, unpredictable outcomes. Therefore, following discussions of the three phases, the analysis will also present a discussion of the emergent outcomes for each 
change. Thus analyzed, the three major changes will systematically capture the process of evolution of Biznally's offshore vendor relationships, and serve as the basis for a discussion of its implications in Section 4.

Table 1 summarizes Biznally's three morphogenetic change cycles, and the discussion below expounds on the nature of each.

\subsection{Organizational Change A-implementation of captive offshore service center}

\subsubsection{Morphogenesis Phase A1: Structural and Cultural Conditioning}

A long history of industry stability in Biznally's traditional credit report product space had bestowed upon upper management the luxury of coming to expect uninterrupted market growth. Successive, ambitious growth targets were thus set as ongoing objectives. Given that the company was already a near monopoly in a large market, these targets were usually achieved, but generally at the continual expense of operational efficiency. Over several years, upper management's single-minded pursuit of the 'top line' had nurtured an organization-wide tolerance for structural redundancies, resulting in a plethora of decentralized support units, ostensibly to service separate customer segments. In practice, however, these support units operated relatively independently with their own agendas, often with overlapping scope, and with little regard to mutual duplication of functions. The free-for-all approach fostered by such a structure was quite palpable at both the business and IT levels. At the business level, it was evidenced by an ad hoc philosophy to contractual negotiations and sales. At the IT level, it was manifested as a lack of systematic interactional processes for user departments to follow in requesting and obtaining applications support, despite the obvious criticality of Biznally's applications portfolio to its business model.

\subsubsection{Morphogenesis Phase A2: Socio-Cultural Interactions}

Under these antecedent circumstances, Biznally's decision to establish TEC, its captive offshore subsidiary, emerged from the confluence of two separate but compatible notions originating respectively from upper management and IT management. As described earlier, upper management had adopted a laissez faire approach for many years, which had propagated organization-wide systemic inefficiencies. The resulting build-up of cost pressures, which were severely exacerbated by an enduring economic downturn, had caused them to fervently search for new ways of cutting costs. During this search, it was rediscovered that the company had significant funds tied up in an as yet undefined initiative in an overseas region known globally for its technology offshoring services industry. The decision that seemed to logically suggest itself to management was for these committed funds to be refocused toward establishing an offshore tech subsidiary, which could earn the company some additional income from a new line of business, thus alleviating some cost pressures.

Concurrently, IT management's motivations in going along with this proposition were two-fold. The first one was a vision for the proposed tech subsidiary to play a dual role, not just as a profit center offering its services to external customers, but also as a major internal support center that would provide Biznally's own users with applications development and related services. IT's other motivation stemmed from the prospect of being able to maintain close control over a captive vendor, a desire rooted in organizational tradition. For a number of years, the IT group had regularly offshored some development and support work to overseas vendors, but under arrangements for key vendor personnel to physically work from Biznally's onshore premises. These arrangements were driven by IT management's strong belief in the power of 'staff supplementation' to bridge geographically separated personnel into cohesive work groups. The company's experiences had borne out this belief - such arrangements had historically enabled Biznally's IT group to apparently work closely with its offshore vendors.

"A lot of the work in earlier years... was done on shore. Staff supplementation. So really what they were doing is they were taking consultants out of India, bringing them here, putting them in dormitory types of accommodations, and they were still working on Biznally premises. And the value of doing this - doesn't there aren't more effective ways of doing it - was that Biznally employees started to get a sense of how they would work with people."

(Director of Product Development Technology)

"In the early years we limited the amount of proprietary technology that we let the vendors touch, but over a period of time we let them see just about everything."

(Chief Technology Officer, Asia-Pacific)

Going forward, the vision was that a captive subsidiary would not only enable IT to retain vendor control, but also help lower its operating costs further, given the prevailing international labor arbitrage opportunities. In addition, a fully staffed subsidiary would also serve as a larger resource pool, given that Biznally's own personnel were frequently tied up in forward looking 'investment' initiatives.

\subsubsection{Morphogenesis Phase A3: Structural and Cultural}

\section{Elaboration}

Given these imperatives on the part of upper management and IT management, Biznally went forward with a decision to establish a new overseas subsidiary as envisioned. This new unit, known as TEC, was accorded an initial mission of providing the parent company with general services in technology management, as well as specific services pertaining to application development, testing, and management. Biznally's relationship with its dedicated, captive vendor was structured on the basis of three key predicating principles. First, in order to exert maximum cost leverage on the vendor, it was stipulated that the center would compete for the parent company's business with other, independent vendors. Second, seemingly in line with the company's laissez-faire customs, Biznally's IT management proclaimed that various segments of Biznally's distributed technology team could consider themselves fully empowered to conduct 'one-off' negotiations directly with the subsidiary's staff, and to work out separate, independent arrangements for requested services, which ranged from a few thousand dollars to several hundred thousand dollars. Third, in a continuation of its erstwhile offshoring practices, IT management arranged for key TEC personnel to work in onshore teams on Biznally's U.S. premises, side-by-side with its own in-house application specialists.

From Biznally's perspective, these three operating principles represented established practices that had worked well before in its relationships with third party offshore vendors. It therefore fully expected its new relationship to be a fruitful one, based as it was on similar grounds. However, the company did not quite grasp the reality of the modified situation - i.e., the fact that the interorganizational context had undergone a subtle change, in which its fragmented relationships with third party vendors had now been replaced with a new consolidated relationship with its own captive subsidiary instead. Given the overheads associated with such a hierarchical relationship, tapping into its benefits called for a somewhat different, more disciplined approach - one that was more planned and centralized. Nevertheless, viewing its subsidiary sometimes as an overseas extension of its in-house staff (in allowing ad hoc negotiations) and at other times as a third-party vendor (in requiring it to compete with other vendors), Biznally never quite fully acknowledged the reality of the transition that 
Table 1

Three morphogenetic cycles in Biznally's offshore vendor relationships.

\begin{tabular}{|c|c|c|c|}
\hline & $\begin{array}{l}\text { Structural and Cultural } \\
\text { Conditioning }\end{array}$ & Socio-Cultural Interactions & $\begin{array}{l}\text { Structural and Cultural Elaboration; Emergent } \\
\text { Outcomes }\end{array}$ \\
\hline \multirow[t]{2}{*}{ Morphogenetic change cycle A } & $\begin{array}{l}\text { - Historically benign } \\
\text { environment at Biznally } \\
\text { engendered upper management } \\
\text { expectations of continual 'top } \\
\text { line' market growth }\end{array}$ & $\begin{array}{l}\text { - Enduring economic } \\
\text { downturn magnified } \\
\text { inefficiencies and exerted } \\
\text { severe cost pressures on upper } \\
\text { management, resulting in } \\
\text { consideration of redirecting } \\
\text { committed overseas funds to } \\
\text { establish offshore tech center }\end{array}$ & $\begin{array}{l}\text { - Relationship with captive tech center } \\
\text { actualized on three principles - (a) that the } \\
\text { 'vendor' would need to compete for Biznally's } \\
\text { business, (b) that it would be required to } \\
\text { conduct one-off negotiations separately with } \\
\text { various tech teams distributed throughout } \\
\text { client organization, and (c) that some of its key } \\
\text { personnel would need to work out of Biznally's } \\
\text { onshore premises, in 'staff supplementation' } \\
\text { mode }\end{array}$ \\
\hline & $\begin{array}{l}\text { - Resultant organizational } \\
\text { decentralization; high } \\
\text { tolerance for ad hoc processes } \\
\text { and systemic inefficiencies }\end{array}$ & $\begin{array}{l}\text { - IT management found this } \\
\text { proposition attractive, due to } \\
\text { potential for having a tightly } \\
\text { controlled subsidiary provide }\end{array}$ & $\begin{array}{l}\text { - Inconsistent notions behind these principles } \\
\text { betrayed Biznally's ambiguities regarding } \\
\text { vendor's role, and created cost, coordination, } \\
\text { and control issues }\end{array}$ \\
\hline
\end{tabular}

applications support at

costs

- The confluence of these two agendas led to organizational decision to proceed with offshore tech center

- Biznally's strategic rethink, engendered by persistent economic conditions, culminated in identification of non-core LOBs for divestiture

- Underperforming offshore tech center caught management's eye, which sold it off to the overseas conglomerate Knowlaware

- The newly independent tech center continued to serve Biznally, together with a few other clients

- Trust built-up over two year time frame enabled Biznally to let the vendor now complete some tasks entirely offshore. However, it also retained some control over Knowlaware, by way of tight specifications, close oversight, competitive bidding practices, and continued staff supplementation - To spread risk, Biznally simultaneously cultivated new relationships with several other offshore vendors, albeit only for overflow maintenance tasks characterized by fixed price, small scope, clear requirements, and the use of 'commodity' technologies

Agreements reached with two select vendors Knowlaware and N-Stint - to previous change cycle deteriorated several of Biznally's offshore vendor relationships. To stem this, Biznally sought the assistance of a global management and technology company

- Biznally and the consultant mutually came up with an Application Management Plan,anchored to a core set of non-negotiable principles. One principle stipulated that Biznally would replace its multiple vendor relationships with closer working ties with fewer offshore vendors, and have them commit to a pre-defined set of service levels
Knowlaware and N-Stint -
implement the new plan

- Biznally would seed these relationships by helping both vendors respective offshore locations. Benefits expected by Biznally - (a) exposure to centers' best development practices, and (b) highest priority to be accorded to Biznally's work requests. Benefits expected by vendors liberty to leverage centers' expertise for pursuing additional business
- A fragmented approach and lack of overarching discipline in regards to vendor governance led to mixed project outcomes over a two year period

- Despite spreading risk, Biznally ignored inter-organizational processes that would help it systematically transition from one offshore vendor to several, competitive vendors. A key omission - the failure to standardize process interfaces for its new relationships

- An increasingly complex mix of unconnected ad hoc arrangements between Biznally and its various offshore vendors led to ever greater confusion and unpredictability, to which it responded with more and more detailed contractual clauses

- Governance by clauses proved to be an ineffective approach. Notwithstanding a few heroic efforts by individual project managers, leading to a handful of successful outcomes, the lack of standardized vendor processes generally translated into unclear information requirements, poor communication, and unintended consequences such as excessive task iterations, schedule and cost slippages, and overall uncertainty

- To ensure plan success, Biznally retained in-house skills pertaining to project leadership and oversight, planning and knowledge transfer, systems analysis, strategic and infrastructure design, quality assurance, final testing, and system stabilization. To steer its applications personnel in these directions and away from coding, it worked with them to develop career change plans oriented toward such higher order skills

- Biznally's other actions to ensure success -

(a) minimizing timeline and deadline changes in ongoing projects, and (b) an explicit acknowledgment to its clients that the ultimate responsibility for offshored work would be solely its own 




had taken place. The overall impression created was thus one of ambivalence and ambiguity.

Due to these contradictions, coordination and cost issues soon began to surface. For example, Biznally's ad hoc approach to negotiations and transactions in connection with service and support requests resulted in the proliferation of a varied mix of contractual arrangements with the subsidiary, with few commonalities or consistencies. Despite this, Biznally continued to ignore the need for more streamlined processes to govern its interactions with TEC. This oversight detrimentally impacted coordination efficiencies, not only in a direct manner, but also indirectly since it inadvertently communicated the wrong message that the parent company had few concrete expectations of the vendor regarding processes for service requests and fulfillment. Furthermore, the company's decision to have TEC personnel work onshore made for mixed messages. On the one hand, it purveyed a prima facie desire for better inter-organizational coordination. On the other, however, it was naïvely incongruent with Biznally's lack of attention to the need for establishing concerted support processes. In addition, the consultant-like compensation structure of the staff supplementation model also substantially racked up overall support costs.

\subsubsection{Emergent outcomes of organizational Change $A$}

Biznally's decision to have onshore work teams comprised of its own specialists as well as TEC personnel created some welcome operational efficiencies. These gains, however, were offset considerably by the company's haphazard tactics on the contractual front. This engendered a number of unsuccessful project outcomes, mixed with some successes. The first two years of Biznally's relationship with TEC, therefore, were punctuated by a series of 'starts' and 'stops.' Much later, the company would concede its flawed, fragmented approach, and acknowledge that it would likely have experienced better outcomes if it had paid greater attention to inculcating an overarching discipline centered around contractual and governance processes from the very beginning.

\subsection{Organizational Change B - divestment of center, and transition to multiple vendors}

\subsubsection{Morphogenesis Phase B1: Structural and Cultural Conditioning}

The previous phase of change had seen the emergence of a host of fitful outcomes rather than generally successful ones. The unpredictability that arose from these inconsistencies turned out to play a major role in influencing the subsequent course of events. The persistence of the economic downturn that had begun some years before had caused upper management to engage in a strategic rethink of the company's lines of business, and a renewed focus on its core competencies. Ancillary lines whose performances were less than stellar were summarily deemed as non-core and ripe for divestiture. Technology operations were no exception to this rule, and thus the underperforming offshore tech center came squarely in management's sights. Accordingly, two years after it had established the TEC unit, Biznally spun off and sold it to an overseas conglomerate called Knowlaware, which subsequently restructured the technology center into a local, independent division. Under the acquired name of its parent company, the center continued to serve mostly Biznally, together with a handful of other, extraneous clients.

\subsubsection{Morphogenesis Phase B2: Socio-Cultural Interactions}

Soon after resuming business with its erstwhile subsidiary, Biznally began to loosen some of the control it had exerted in the past. A major part of this took the form of letting Knowlaware take on 
full responsibility for certain projects, and even to complete them entirely offshore. IT management's decisions in this regard were made based on the trust and confidence the company had built up in the vendor's capabilities during the time the latter had served as a captive applications support center. However, as its largest customer, Biznally was also cautious enough to retain other control through tight job specifications, close oversight, and continued competitive bidding practices. In addition, it ensured that it continued to be in a position to monitor the projects it handed off to Knowlaware, by once again requiring designated members of the vendor's technical staff to work onshore from Biznally's premises.

Despite a somewhat relaxed relationship, Biznally exhibited a degree of wariness of fostering an exclusive dependence on its old vendor partner. It also considered it unlikely that under its new ownership, the vendor could continue to provide Biznally with the same level of service as it had done before. In order to reduce its dependence on Knowlaware, therefore, it decided to spread some applications work out elsewhere. To that end, it moved to cultivate new relationships with other overseas vendors. On this newer front, though, Biznally displayed a tendency to revert to a defaultlike risk-averse outlook. For instance, it would assign work to these vendors only when there was a shortfall of available internal personnel - in other words, 'overflow' projects for which it simply did not possess enough resources. Such projects did not appear in regularity, but tended to follow short, temporary spikes. The company's conservative approach was also evident in the nature of applications work it tended to hand off to these newer vendors small, fixed-price, 'problem-ticket' contracts for applications development/maintenance, of contractual values worth $\$ 100,000$ or less, and with expected completion times of no more than three months, all overseen by Biznally. Altogether, these projects amounted to no more than $2-3 \%$ of the company's applications portfolio. In addition, Biznally always retained analysis and architectural design activities in-house, such that offshore vendors were assigned coding and basic testing responsibilities only. It also took care to ensure that most work sent out represented stable, 'commodity' technologies, such as the legacy systems job control language CICS, the database DB2, the programming language COBOL, and "credit risk management' legacy applications, which supported Biznally's highly structured, core business processes. Finally, the company avoided sending out projects whose information requirements were not very clearly defined, those whose specifications were subject to change, or those that were based on specialty/niche technologies.

\subsubsection{Morphogenesis Phase B3: Structural and Cultural Elaboration}

Notwithstanding the above conservative actions vis-à-vis its new offshore vendors, as had been the case with the company's previous shift from in-house support to a captive vendor, Biznally paid little heed to the redesign of the requisite inter-organizational processes that would have helped it systematically operationalize the multiplicity of new vendor connections and relationships. The company's failure to standardize its process interfaces in transitioning from one vendor to relationships with several, competitive vendors led to ever greater confusion, given an increasingly complex mix of unconnected, ad hoc arrangements between local company units and various offshore vendors. The company's essential response to the unpredictability stemming from this variance was to add more and more detailed clauses into its contracts.

"And you can institute additional clauses in the contracts, basically make the vendor take the risk, but that's just pushing the penny from one side to the other."

(Assistant Vice President of Development)

\subsubsection{Emergent outcomes of organizational Change $B$}

Biznally's relative inattention to a discipline for interorganizational processes translated into enormous variations in the outcomes of project initiatives. Relying largely on the 'heroic efforts' of individual project managers, they ranged from spectacular successes to clear failures. Despite such occasional extraordinary labors, relationship ambiguities and non-standard vendor processes often snowballed into unclear information requirements, and poor communication on mutual expectations, success measures, and contingency scenarios/actions. Moreover, increasingly cumbersome contracts generated unintended consequences, including skepticism on both sides, erosion of vendor goodwill, and high overhead costs of monitoring/enforcement. In spite of the careful selection of mature, well-defined, and structured tasks, therefore, project environments over the next two year period were beset by excessive task iterations, inordinate schedule slippages, cost overruns, and overall uncertainty.

"Because we didn't have the optimized relationship and the processes, each time the iteration occurred, tons of requirements were uncertain. The cost of the iteration was very expensive so we had cost overruns. And deadline slips."

(Senior Vice President of Development and Support)

\subsection{Organizational Change C - closer relationships with select vendors}

\subsubsection{Morphogenesis Phase C1: Structural and Cultural Conditioning}

Stung by adverse project outcomes and the degeneration of several of its offshore vendor relationships, as well as under upper management pressure, Biznally's IT group sought the services of a global management and technology consulting company to provide it with guidance for taking corrective actions and regaining some control over offshoring. After extensive deliberations with the consultant, it was agreed that the undertaking of remedial measures called for a cohesive plan to guide Biznally's future offshoring initiatives. Consequently, a team comprised of client and consultant representatives was put together and assigned the responsibility of crafting such a plan. The outcome of this joint team's efforts was the production of an Application Management Plan, a highlevel document whose contents were anchored to non-negotiable guiding principles. A core principle in this list entailed the identification of, and commitment to, a set of service levels that would hereafter serve as the basis for all contractual agreements between Biznally and its offshore vendors. To enhance their feasibility, Biznally was to detach itself from unworkable vendor relationships, and to simultaneously nurture closer working ties with a handful of select applications development vendors.

\subsubsection{Morphogenesis Phase C2: Socio-Cultural Interactions}

Two such vendors were identified following an elaborate vetting process. One was Knowlaware, which by then had evolved into a reputed offshore provider of basic applications development services. Having also recently gone public, it had come into its own, with a new standalone identity and an assurance of professional management backed by shareholders. The other was Knowlaware's competitor, N-Stint, which had recently established a global presence and a reputation for cutting edge, quality work. Both were already doing business with Biznally, but the vision was for these two vendors to gradually take over most of Biznally's applications development and maintenance work, starting with the most important applications, using a prioritization system to be jointly negotiated. Biznally's rationale behind a dual vendor strategy was to foster a competitive-like environment while simultaneously reaping the advantages of a close inter-organizational alliance. 
"We ended up with two companies, Knowlaware and N-Stint. Because one of the things we wanted to do was to have the option of moving work between vendors. We just felt that in negotiation, one of the things that we felt strongly about is... even though we hardly ever moved anything between vendors, we generally wanted to keep the vendors on their toes."

(Assistant Vice President of Development)

After both vendors had committed to Biznally's long-term vision, it was jointly decided that the requisite closer working relationships would be fostered by having Biznally facilitate the establishment and ongoing operations of a Center for Software Excellence (CSE) at the respective offshore locations of both vendors. The benefit to Biznally from this arrangement would be that it would benefit from the centers' orientation to best development practices. The benefit to the vendors was envisaged as their complete liberty to leverage the resident expertise of their centers to pursue additional business, as long as it was understood that Biznally's needs were to consistently be accorded the highest priority.

To ensure the successful implementation of its Application Management Plan, Biznally decided to put in place rigorous methodologies for information needs assessment and capture, and to revisit all its legacy applications documentation. Its expectation was that this would enable the two vendors to anchor all maintenance work and fixes to strictly defined measures of problem severity, and to code programs in close conformance to defined requirements. On their part, both vendors made commitments to institute sound maintenance management practices that would adequately address hardware and software tools, codes, components, standards, repeatable procedures, testing environments, quality, and internal coordination mechanisms. It was also understood by all parties that the effectiveness of the overall plan and framework would be assessed along various measures of vendor performance, such as responsiveness, adherence to specifications, need for delivery iterations, reworks and refixes, timely project completion, budget variance, defect rate, and/or operational failures.

\subsubsection{Morphogenesis Phase C3: Structural and Cultural \\ Elaboration}

In implementing the plan, Biznally retained crucial in-house skills pertaining to project leadership and oversight, planning and knowledge transfer, systems analysis, strategic and infrastructure design, quality assurance, final testing, and system stabilization. Congruently, it worked with its in-house applications personnel on career change plans to help them shift their skills away from coding for maintenance and development, and to re-orient them to such higher-order tasks. Other commitments made by the company included minimizing changes to timelines and deadlines, and an explicit acknowledgment to its clients that the ultimate responsibility for any offshored work on their behalf was solely its own. Further, the CSE centers of the two vendors ended up operating as large-scale personnel repositories of expertise, organized by skillsets in specific technologies, tasks, and/or domains/subjects. For specific projects, individuals were drawn from these resource pools into operational teams, which were held accountable not just for particular areas of expertise, but also individually and collectively to the actual services contracted for, at the service levels stipulated. Last but not least, Biznally and the two vendors collaboratively developed a meticulous 'software solutions framework,' clearly outlining the respective roles and responsibilities of all Biznally and vendor personnel in each future offshored project.

"Then as you get better at it, you then start to have a generally accepted process. And therefore it could be done by mere mortals." (Senior Vice President of Development and Support)

\subsubsection{Emergent outcomes of organizational Change $C$}

Biznally's implementation of its applications management plan was quite successful. As a result of its newly 'optimized' interorganizational processes, it was able to entrust increasingly greater responsibility to Knowlaware, and eventually to N-Stint as well. It began to experience more positive outcomes, even for projects with uncertain requirements. Gradually, its relationship with these two vendors transitioned away from contractual, transactional types of arrangements, to more trust-based, permanent affiliations resembling inter-organizational alliances. Over the following six years, a projects discipline, as codified in the plan and solutions framework, was internalized by all three organizations to such an extent that tasks offshored by Biznally became larger, strategic, and cutting edge in nature. Concurrently, the distribution of responsibilities came to be weighted heavily with the two vendors, who often took on full responsibility for entire projects, including business analysis, architecture design, as well as project management. Specific activities would often be carried out in hybrid offshore-onshore mode, with no constraints due to the formal organizational boundaries separating Biznally and its two vendors. This complete turnaround enabled Biznally's senior managers to drastically reduce its onshore personnel, resulting in tremendous cost savings.

Despite their satisfaction, one new concern being voiced the time of this study was that an excessive reliance on its vendors had drained a valuable domain knowledge base away from the company. There was a growing awareness that communication and collaboration issues resulting from Biznally's lack of control over its vendors were starting to adversely affect quality assurance, particularly given that the vendors were handling more 'greenfield' projects than ever before. A common refrain being heard was that there were no policies and procedures in place at Biznally for retaining and transferring the subtle business and domain knowledge that were critical to the success of cutting edge technology projects. Such rumblings, if continued, held the distinct potential to transform into nascent emergent outcomes. Such outcomes could subsequently engender yet another morphogenetic cycle, perhaps confronting Biznally's decision makers with the dilemma of whether or not to take a few steps back from the company's carefully nurtured vendor relationships.

\section{Implications and discussion}

A systematic analysis of the evolution of Biznally's interorganizational relationships with offshore vendors has uncovered a sequence of three major organizational changes in the progression. Each change was comprised of a morphogenetic cycle of three phases, where an initial set of Structural and Cultural Conditions interacted with socio-cultural dynamics to precipitate decisions/actions whose impacts consolidated or altered the structural and cultural landscape. In each cycle, the foundation for change was laid in the first phase where emergent outcomes of previous change cycles conditioned the overall decision and action context. In the second phase, the conditioned context interacted with socio-cultural dynamics among the system's actors, and the degree of convergence or divergence between the two influenced the extent to which undertaken managerial decisions and actions effected real structural and cultural change. Further change often occurred during the transition from the second to the third phase, depending on whether the emergent consequences of undertaken decisions and actions were congruent or incongruent with the structural and cultural changes initiated in the second phase. This analysis, therefore, has provided a holistic, critical-realist view of the organizational changes underlying the evolution of Biznally's relationships with its offshore vendors. Its explanatory approach meets the major objective of this study, which was to ascertain 'how' Biznally's offshoring relationships transformed over time. The 
resulting analytical narratives have been presented here impartially, but it is important to note that since their generation was heavily reliant upon information provided by the client's representatives, it is conceivable that key vendor perspectives were not been captured quite well enough. As the literature notes, vendor viewpoints provide an invaluable foil to client perspectives in acquiring better understandings of relationship intricacies (Levina \& Ross, 2003; Plugge \& Bouwman, 2012; Plugge, Wijers, \& Wagenaar, 2008).

For organizational Change A, Biznally's switch from in-house applications support to the offshore TEC unit was apparently fraught with ambivalence about the latter's role. On the one hand, its status as a captive, dedicated vendor suggested a power asymmetry or inequity weighted heavily in the client's favor. On the other, though, its mandate to earn Biznally's business on the open applications support market seemed to place it on par with the client as its equal. While the latter highlights the company's risk aversion (something Biznally is known for), its combination with the former created a conflict of logic in its intent toward the vendor relationship.

The other, related factor that generated ambiguity in organizational Change A was TEC's offshore location, coupled with the fact of its personnel working hand-in-hand with Biznally employees in hybrid, onshore teams. The vendor's overseas location undoubtedly created the potential for integration constraints on signification and interpretation structures of the relationship. Biznally's decision to have its applications personnel work in staff supplementation mode probably represented a countering mechanism aimed at preempting these constraints with a liaison structure. The use of this bridging mechanism was also consistent with the unrestricted, laissez-faire contractual arrangements between the subsidiary and various segments of Biznally's technology staff. However, the fact that the vendor had been set up as an overseas subsidiary and had to compete for the client's business continued to send the complete opposite message, as did Biznally's cautious, conservative decision to let the vendor work only on small coding projects pertaining to stable, credit risk management applications. These mixed messages were exacerbated by a lack of systemic operational processes for requesting and obtaining applications support. In summary, although the individual pieces of Biznally's actions may have made sense if considered in isolation from each other, they were inconsistent rather than cohesive when considered collectively. These inconsistencies essentially stemmed from the company's apparent uncertainty and confusion regarding the vendor's true role. They were primarily responsible for the mixed outcomes of organizational Change $\mathrm{A}$, as well as its ultimate instability.

During organizational Change B, TEC's confused status dissolved into clarity, having undergone a sharp transition from a captive, dedicated support unit to an independent vendor that continued its transactions with Biznally under the new name of Knowlaware. This move, part of the client company's strategy to return to its core competencies, provided it with a good opportunity to redefine its relationship with the vendor. Having just come out of a hierarchy/equity arrangement, this left it with two broad options-a formal, arms-length, market relationship, or a close-knit, informal, business-partner-like arrangement (Powell, 1990). Either option was feasible at this point, given the unique, hybrid arrangements of the previous phase. Going with the market option would have entailed putting together a systematic framework to consistently follow for all offshored work, including formal policies, processes and procedures for task identification, work hand-off, information sharing, project management, monitoring and control, as well as outcomes assessment. On the other hand, a partner-like arrangement might also have benefitted from such a framework, but would additionally have required a greater focus on inter-organizational processes and routines for working together.
Biznally did not fully commit to either of the two divergent options. Some of its actions were aligned with the first option, while others were more suited to the second one. It appeared to have opted for a market-like relationship in offshoring only commodity technologies, legacy applications, and well-defined, overflow coding/testing work. However, it also had the vendor's personnel work onshore in staff supplementation mode again, perhaps in an effort to mitigate the possible effects of cultural barriers. Most perplexing of all, though, was its decision to reduce its dependence on Knowlaware by expanding its repertoire of offshore vendors, without first putting a system or framework in place to govern the activities all these new relationships would necessitate. This was particularly egregious in light of the fact that Biznally's prior experiences had given it ample opportunity to realize the shortcomings of such an omission, due to similar mistakes it had made with TEC/Knowlaware. One possible explanation is that the company's orientation during this period may have been excessively focused on controlling the vendor, rather than on instituting well considered governance mechanisms. For instance, it was not until much later, after it had noted the futility of countering unpredictable outcomes with increasingly detailed contractual clauses, that the company realized the criticality of a formal disciplinary framework for inter-organizational oversight. In its place, the weight of all the additional contractual clauses inevitably led to dissatisfaction and friction, culminating in time and budget setbacks.

After the first two rounds of organizational changes, Biznally tapped the services of a management and technology consultant to bring it out of its inertial inconsistencies and resistance to change. The Application Management Plan comprising organizational Change $C$ entailed a total re-examination of all of the company's inter-organizational assumptions. Its tangible core of service level agreements, together with a new resolve to forge close alliances with a few vendors, steered it firmly in the direction of a network-like business partnership with its two select vendors, Knowlaware and N-Stint. Commitments made by Biznally to invest in certain specific methodologies and processes were reciprocated by complementary commitments from both vendors. Clear linkages between the structural changes and Biznally's decisions and actions gave consistency and legitimacy to these changes. This laid the foundation for revised, positive expectations on both sides, further accelerating the change process. Trust-based relationships, consolidated by rigorous disciplines of information needs assessment, information sharing, well-defined expectations, and clear measures of outcomes ensured the growing success of both vendor relationships. Even the perceived drain of knowledge away from the company to its vendors was communicative of a silver lining, namely, that the vendors had done such a good job of managing its applications that the company had let its knowledge base slip away from it.

\section{Conclusion}

A morphogenetic analysis of the evolution of Biznally's vendor relationships over a six year period has uncovered the interplays among key factors in this process, and shed light on the overall direction of the three organizational changes in the progression. The company's desire for effectiveness with its long time vendor took it through two intermediate rounds of change before it was able to establish an optimal relationship. In the first round, the client company did many things right but its flawed conception of the vendor's identity and role in the relationship derailed the endeavor. In the second, it came to grips with the vendor's separate identity, but once again, its desire to control the independent vendor too closely backfired as a tactic. Finally, with the assistance of a consulting organization, it learned how to formulate and implement a comprehensive relationships discipline, which it was able to 
apply effectively toward strong continuing relationships with two vendors.

These findings support the basic premise of the study, i.e., the contention that achieving relationship effectiveness requires a deeper understanding of the organizational mechanisms by which such factors potentially operate. They also validate the application of the morphogenetic change framework to discover these mechanisms, in two different ways. First, the framework helped uncover what was at work behind Biznally's imperfect inter-organizational vendor relationships. It showed that the true barriers to effective client-vendor relations were subtle cultural mechanisms rather than overtly structural ones. Specifically, ineffectual relationship outcomes had more to do with Biznally's own perceptions of such associations, as well as its ideas on how they might be used, rather than any objective linkage attributes. Second, the framework's cultural lens also revealed the true role played by Biznally's consultant in helping it turn around its vendor relationships. It brought out the fact that the value provided by the consultant's intervention lay not in the provision of any technical expertise, but rather in effecting organizational change mechanisms aimed at shifting Biznally's dysfunctional perceptions and replacing them with an enabling mindset.

\section{References}

Alami, A., Wong, B., \& McBride, T. (2008). Relationship issues in global software development enterprises. Journal of Global Information Technology Management, 11(1), 49-68.

Archer, M. (1982). Morphogenesis versus structuration: On combining structure and action. The British Journal of Sociology, 33(4), 455-483.

Archer, M.(1988). Culture and agency: The place of culture in social theory. Cambridge, UK: Cambridge University Press.

Archer, M. (1995). Realist social theory: The morphogenetic approach. Cambridge, UK: Cambridge University Press.

Archer, M. (2010). Morphogenesis versus structuration: On combining structure and action. The British Journal of Sociology, 61(s1), 225L 252.

Avison, D., \& Banks, P. (2008). Cross-cultural (mis)communication in IS offshoring: Understanding through conversation analysis. Journal of Information Technology, 23(4), 249-268.

Basden, A. (2011). Enabling a Kleinian integration of interpretivist and socio-critical IS research: The contribution of Dooyeweerd's philosophy. European Journal of Information Systems, 20(4), 477-489.

Beckinsale, M., \& Ram, M. (2011). ICT adoption and e-business development: Understanding ICT adoption amongst ethnic minority businesses. International Small Business Journal, 29(3), 193-219.

Beulen, E., Ribbers, P., \& Roos, J. (2011). Managing IT outsourcing. Oxford, UK: Routledge.

Beulen, E., Tiwari, V., \& van Heck, E. (2011). Understanding transition performance during offshore IT outsourcing. Strategic Outsourcing: An International Journal, 4(3), 204-227.

Bhaskar, R. (1975). A realistic theory of science. York, England: Leeds Books.

Bhaskar, R. (1979). The possibility of naturalism: A philosophical critique of the contemporary human sciences. Atlantic Highlands, N.J.: Humanities Press.

Bridgman, T., \& Willmott, H. (2006). Institutions and technology: Frameworks for understanding organizational change-the case of a major ICT outsourcing contract. The Journal of Applied Behavioral Science, 42(1), 110-126.

Burns, B. (2008). Offshoring: Secure or open to the praying mantis? Strategic Outsourcing: An International Journal, 1(1), 77-86

Carlsson, S., Henningsson, S., Hrastinski, S., \& Keller, C. (2011). Socio-technical IS design science research: Developing design theory for IS integration management. Information Systems and eBusiness Management, 9(1), 109-131.

Cha, H., Pingry, D., \& Thatcher, M. (2008). Managing the knowledge supply chain: An organizational learning model of information technology offshore outsourcing. MIS Quarterly, 32(2), 281-306.

Davis, G., Ein-Dor, P., King, W., \& Torkzadeh, R. (2006). IT offshoring: History, prospects and challenges. Journal of the Association for Information Systems, 7(11), 770-795.

De Vaujany, F.-X., Walsh, I., \& Mitev, N. (2011). An historically grounded critical analysis of research articles in IS. European Journal of Information Systems, 20(4), 395-417.

Dobson, P.(2001). The philosophy of critical realism: An opportunity for information systems research. Information Systems Frontiers, 3(2), 199-210.

Dobson, P., Myles, J., \& Jackson, P. (2007). Making the case for critical realism: Examining the implementation of automated performance management systems. Information Resources Management Journal, 20(2), 138-152.

Edwards, T. (2007). A critical account of knowledge management: Agentic orientation and SME innovation. International Journal of Entrepreneurial Behaviour and Research, 13(2), 64-81.
Fox, S. (2009). Applying critical realism to information and communication technologies: A case study. Construction Management and Economics, 27(5), 465-472. Gewald, H., \& Dibbern, J. (2009). Risks and benefits of business process outsourcing: A study of transaction services in the German banking industry. Information and Management, 46(4), 249-257.

Gupta, A., Seshasai, S., Mukherji, S., \& Ganguly, A. (2007). Offshoring: The transition from economic drivers toward strategic global partnership and 24-h knowledge factory. Journal of Electronic Commerce in Organizations, 5(2), 1-23.

Haried, P., \& Ramamurthy, K. (2009). Evaluating the success in international sourcing of information technology projects: The need for a relational client-vendor approach. Project Management Journal, 40(3), 56-71.

Kakabadse, N., Kakabadse, A., \& Kouzmin, A. (2007). Designing balance into the democratic project: Contrasting Jeffersonian democracy against Bentham's panopticon centralisation in determining ICT adoption. Problems and Perspectives in Management, 5(1), 4-28.

Kelly, S., \& Noonan, C. (2008). Anxiety and psychological security in offshoring relationships: The role and development of trust as emotional commitment. Journal of Information Technology, 23(4), 232-248.

Kotlarsky, J., \& Oshri, I. (2008). Country attractiveness for offshoring and offshore outsourcing: Additional considerations. Journal of Information Technology, 23(4), 228-231.

Lacity, M., Willcocks, L., \& Khan, S. (2011). Beyond transaction cost economics: Towards an endogenous theory of information technology outsourcing. Journal of Strategic Information Systems, 20(2), 139-157.

Levina, N., \& Ross, I. (2003). From the vendor's perspective: Exploring the value proposition in information technology outsourcing. MIS Quarterly, 27(3), 331-364.

Markus, M., \& Silver, M. (2008). A foundation for the study of IT effects: A new look at DeSanctis and Poole's concepts of structural features and spirit. Journal of the Association for Information Systems, 9(10), 609-632.

Mathew, S. (2011). Mitigation of risks due to service provider behavior in offshore software development. Strategic Outsourcing, 4(2), 179-200.

Mingers, J. (2000). The contribution of critical realism as an underpinning philosophy for OR/MS and systems. The Journal of the Operational Research Society, 51(11), 1256-1270.

Mitev, N., \& de Vaujany, F.-X. (2012). Seizing the opportunity: Towards a historiography of information systems. Journal of Information Technology, 27(2), 110-124.

Mora, M., Gelman, O., Forgionne, G., Petkov, D., \& Cano, I. (2007). Integrating the fragmented pieces of IS research paradigms and frameworks: A systems approach. Information Resource Management Journal, 20(2), 1-22.

Morton, P. (2006). Using critical realism to explain strategic information systems planning. Journal of Information Technology Theory and Application, 8(1), 1-20.

Mourmant, G., Gallivan, M., \& Kalika, M. (2009). Another road to IT turnover: The entrepreneurial path. European Journal of Information Systems, 18(5), 498-521.

Mutch, A. (2002). Actors and networks or agents and structures: Towards a realist view of information systems. The Interdisciplinary Journal of Organization, Theory and Society, 9(3), 477-496.

Mutch, A. (2010). Technology, organization, and structure: A morphogenetic approach. Organization Science, 21(2), 507-520.

Oshri, I. (2011). Offshoring strategies: Evolving captive center models. Cambridge, MA: MIT Press.

Plugge, A., \& Bouwman, H. (2012). Fit between sourcing capabilities and organizational structure on IT outsourcing performance. Production Planning and Control, 1-13. http://dx.doi.org/10.1080/09537287.2011.648489

Plugge, A., Wijers, G., \& Wagenaar, R. (2008). Exploring IT outsourcing: How client developments affect supplier capabilities. In I. Oshri, J. Kotlarsky, \& L. Willcocks (Eds.), Outsourcing global services: Knowledge, innovation and social capital (pp. 71-95). London: Palgrave Macmillan.

Powell, W. (1990). Neither market nor hierarchy: Network forms of organization. In B. Staw, \& L. Cummings (Eds.), Research on organizational behavior (pp. 295-336). Beverly Hills, CA: Sage.

Ramanujan, S., \& Sandhya, J. (2006). A legal perspective on outsourcing and offshoring. Journal of American Academy of Business, 8(2), 51-58.

Rashid, A. (2012). Offshore outsourcing of IT services as new service development. Journal of Organizational Change Management, 25(3), 445-461.

Smith, M. (2010). Building institutional trust through e-government trustworthiness cues. Information Technology and People, 23(3), 222-246.

Stahl, B., Tremblay, M., \& Lerouge, C. (2011). Focus groups and critical social IS research: How the choice of method can promote emancipation of respondents and researchers. European Journal of Information Systems, 20(4), 378-394.

Volkoff, O., Strong, D., \& Elmes, M. (2007). Technological embeddedness and organizational change. Organization Science, 18(5), 832-848.

Wikgren, M. (2005). Critical realism as a philosophy and social theory in information science? Journal of Documentation, 61(1), 11-22.

Wiredu, G. (2012). Information systems innovation in public organisations: An institutional perspective. Information Technology and People, 25(2), 188-206.

Yin, R. (2009). Case study research: Design and methods (4th ed.). Thousand Oaks, CA: Sage.

Rajesh Mirani is Associate Professor of Information Systems at the Merrick School of Business, University of Baltimore. He holds a PhD from the University of Pittsburgh. His research interests are generally oriented around the broad issue of business and information systems alignment. His present focus is on how organizations manage their offshoring endeavors. He has previously published in Decision Sciences, Information \& Management, Journal of MIS, and MIS Quarterly, among other journals. 